University of Nebraska - Lincoln

DigitalCommons@University of Nebraska - Lincoln

USDA Wildlife Services - Staff Publications

U.S. Department of Agriculture: Animal and Plant Health Inspection Service

$1-1-2021$

\title{
Differing Alterations of Odor Volatiles among Pathogenic Stimuli
}

\author{
Patrick Millet \\ Monell Chemical Senses Center \\ Talia Martin \\ Monell Chemical Senses Center \\ Maryanne Opiekun \\ Monell Chemical Senses Center \\ Gary K. Beauchamp \\ Monell Chemical Senses Center \\ Bruce A. Kimball \\ Monell Chemical Senses Center, bkimball@monell.org
}

Follow this and additional works at: https://digitalcommons.unl.edu/icwdm_usdanwrc

Part of the Natural Resources and Conservation Commons, Natural Resources Management and Policy Commons, Other Environmental Sciences Commons, Other Veterinary Medicine Commons, Population Biology Commons, Terrestrial and Aquatic Ecology Commons, Veterinary Infectious Diseases Commons, Veterinary Microbiology and Immunobiology Commons, Veterinary Preventive Medicine, Epidemiology, and Public Health Commons, and the Zoology Commons

Millet, Patrick; Martin, Talia; Opiekun, Maryanne; Beauchamp, Gary K.; and Kimball, Bruce A., "Differing Alterations of Odor Volatiles among Pathogenic Stimuli" (2021). USDA Wildlife Services - Staff Publications. 2509.

https://digitalcommons.unl.edu/icwdm_usdanwrc/2509

This Article is brought to you for free and open access by the U.S. Department of Agriculture: Animal and Plant Health Inspection Service at DigitalCommons@University of Nebraska - Lincoln. It has been accepted for inclusion in USDA Wildlife Services - Staff Publications by an authorized administrator of DigitalCommons@University of Nebraska - Lincoln. 


\title{
Special Issue: Clinical Science in the Chemical Senses
}

\section{Differing Alterations of Odor Volatiles Among Pathogenic Stimuli}

\author{
Patrick Millet ${ }^{1,2}$, Talia Martin', Maryanne Opiekun', Gary K. Beauchamp ${ }^{1}$ \\ and Bruce A. Kimball ${ }^{1,3, \odot}$
}

\begin{abstract}
'Monell Chemical Senses Center, 3500 Market Street, Philadelphia, PA, USA, ${ }^{2}$ Present address: Technical Resources International, 6500 Rock Springs Drive, Bethesda, MD, USA and 'Previous address: USDA National Wildlife Research Center, 3500 Market Street, Philadelphia, PA, USA
\end{abstract} Correspondence to be sent to: Bruce A. Kimball, Monell Chemical Senses Center, 3500 Market Street, Philadelphia, PA,
United States. e-mail: bkimball@monell.org

Editorial Decision 11 June 2021.

\begin{abstract}
Alterations of the volatile metabolome (the collection of volatiles present in secretions and other emanations) that occur in response to inflammation can be detected by conspecifics and chemometric analyses. Using a model system where mouse urinary metabolites are altered by treatment with lipopolysaccharide (found in the outer cell membrane of gram-negative bacteria), we hypothesized that alteration of body odor volatiles will vary according to the pathogen responsible for inducing the inflammation. We tested this hypothesis by treating mice with different immunogens that engage different immune signaling pathways. Results suggest that alterations of body odor volatiles resulting from inflammation do contain detailed information about the type of pathogen that instigated the inflammation and these differences are not merely dependent on the severity of the inflammatory event. These results are encouraging for the future of differential medical diagnosis of febrile diseases by analysis of the volatile metabolome. In particular, our data support the possibility that bacterial infections can be differentiated from viral infections such that antibiotic drug stewardship could be drastically improved by reducing unneeded treatments with antibiotics.
\end{abstract}

Key words: antibiotic resistance, bodily odors, febrile diseases, infection, inflammation, volatile metabolome

\section{Introduction}

It is well established that bodily odor volatiles (those metabolites originating from urine, glandular secretions, and other sources observed in the vapor phase and detectable by olfaction) is the primary source of social communication for many species (Brennan and Kendrick 2006; Johnston 2003; Kelliher 2007). Behavioral studies have indicated that members of the same species may use these volatile signals to regulate social interactions (e.g., attraction, affiliation, and avoidance). It is also established that these body odors may be influenced by variation in physiological status induced by inflammation, infection, and disease. For example, members of the opposite sex discriminate between odors of sick and healthy individuals, and several studies suggest that female mice are more attracted to the odors of healthy compared to sick males and may actively avoid odors of infected males (Kavaliers et al. 2005).

Similarly, multiple studies have demonstrated that human patients with pathological conditions such as cancer (Bernabei et al. 2008; Bajtarevic et al. 2009; Jezierski et al. 2015), intestinal infection (Burdette and Bernstein 2007), diabetes (Greiter et al. 2010), tuberculosis (Mgode et al. 2012; Mahoney et al. 2013), and other conditions (Bijland et al. 2013) exhibit alterations of body odor. As such, there has been significant interest in recent years in developing chemometric approaches using techniques such as gas chromatography/mass spectrometry, in addition to employing animal 
biosensors, to diagnose illnesses. These chemometric studies rarely reveal the presence of novel volatile metabolites in patient samples (Amann et al. 2014; Kimball 2016), with the notable exception of exhaled breath during pulmonary infection (Phillips et al. 2012; van Oort et al. 2018). Instead, illness regularly results in alteration of the pattern of volatile metabolites present in the healthy state. The origin of these alterations is currently unknown. Furthermore, the specificity of these volatile patterns with respect to individual illnesses has not yet been established. In fact, little is known about the mechanism(s) responsible for alterations of the volatile metabolome.

In rodents, inflammation induced by lipopolysaccharide (LPS, the cell wall material of gram-negative bacteria) impacts the body odor volatile profile (Arakawa et al. 2010; Arakawa et al. 2011a, 2011b; Kimball et al. 2014; Gervasi et al. 2018; Millet et al. 2018). LPS is frequently used in models of inflammation, owing to its ability to produce a robust immune response (Beeson 1947; Geppert et al. 1994; Baldwin 1996; Raetz and Whitfield 2002; Lu et al. 2008). In addition to LPS treatments, we found that treatment with inflammatory cytokines also alters body odor profiles (Millet et al. 2018). Functionally, the changes in body odor induced by LPS can cause healthy conspecifics to avoid the odor of the sick individual (Arakawa et al. 2009a, 2009b).

How inflammation leads to the alteration of body odors is not understood. However, membrane-spanning Toll-like receptors (TLRs) that recognize pathogens according to each microbe's conserved molecular pattern motif are likely involved. For example, TLR4 recognizes gram-negative bacteria by their common LPS exterior. While innate immune responses mediated by TLRs lack the versatility of the adaptive immune response, they can quickly respond to an array of common pathogenic molecules. Upon recognizing their ligand, TLRs rapidly promote the cellular immune response resulting in hallmarks of inflammation, including the release of chemokines and cytokines via one or both of 2 signaling cascades (Figure 1). TLR4 is unique among the Toll-like receptors in that it activates inflammation through both MyD88-dependent

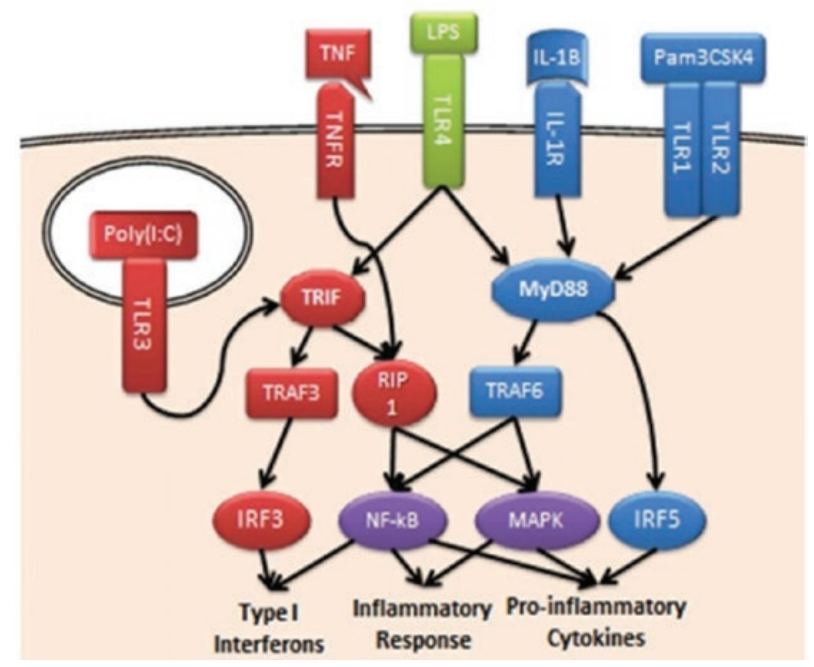

Figure 1. Upon recognizing their ligand, Toll-like receptors (TLRs) rapidly promote inflammation and release of chemokines and cytokines [figure adapted from Lu (2008)]. TLR4 uniquely activates inflammation through both MyD88dependent (blue) and MyD88-independent (red) pathways. Both pathways activate the master regulators of inflammation, NF-kB and MAPK (purple). Other TLRs activate only one of these 2 pathways. MyD88 (blue) also activates IRF5, which helps activate pro-inflammatory cytokines. TRIF (red) produces an immune response directed toward the production of interferons. and MyD88-independent pathways (Lu et al. 2008). Other TLRs activate only one of these 2 pathways. For example, MyD88 activates IRF5, which helps activate pro-inflammatory cytokines such as TNF, IL-6, and IL-12 (Takeda and Akira 2004; Takaoka et al. 2005). The MyD88-independent pathway, mediated by TRIF, produces an immune response directed more toward the production of interferons (Takeda and Akira 2004; Hacker et al. 2006; Choi et al. 2011).

As indicated, we and others have demonstrated that LPS alters body odor (Arakawa et al. 2010; Kimball et al. 2014; Gervasi et al. 2018; Millet et al. 2018). In this and previous studies, we used urine as a representative source of body odor. Urine is considered "a window into the body" and has been demonstrated to be a major source of overall murine body odor (Schaefer et al. 2001; Yamazaki et al. 2002). We hypothesized that distinctive body odor volatile profiles, as observed in urine, would also result from differential TLR recognition and/or stimulation of the MyD88 and TRIF intermediate pathways (Figure 1). To test this, we engaged different immune pathways by treating mice with several molecules known to differentially activate cellular immunity via interaction with specific TLRs. Collectively, these molecules (which, like LPS, are not pathogenic themselves) are among those molecules known as pathogenassociated molecular patterns (PAMPs). In addition to LPS, which activates both MyD88 and TRIF via recognition by TLR4 (responsible for recognition of gram-negative bacteria), we employed 2 PAMPs that individually activate only one of the intermediate pathways (Figure 1). One, the synthetic lipopeptide Pam3CSK4, activates MyD88 (Aliprantis et al. 1999; Brightbill et al. 1999) by way of the TLR2/TLR1 heterodimer (responsible for recognition of gram-positive bacteria). The other, synthetic double-stranded RNA poly(I:C), is a ligand for TLR3 (responsible for recognition of double-stranded viral RNA) and activates TRIF (Alexopoulou et al. 2001). We chose these 2 molecules to determine whether viral and bacterial PAMPs may produce different odorant patterns. If this were the case, it might be possible to design diagnostic volatile analysis platforms to differentiate broad classes of infections.

To test this, we used 2 complementary approaches. First, we trained biosensor animals in a Y-maze to discriminate odor produced by mice injected with a high dose of LPS compared to mice given a vehicle injection (control). The mice were then tasked to apply this learning to the presentation of novel odors resulting from treatment with other PAMPs or lower dose LPS in unrewarded blind generalization trials. These behavioral tests served important purposes. Specifically, we reasoned that if the mice were unable to discriminate by olfaction between LPS-treated mice and mice treated with other PAMPs then it would be highly unlikely that differences could be discerned by gas chromatographic analyses. Consequently, successful behavioral tests justified our going forward with the chemometric work. Successful behavioral tests also would motivate future studies on the communicatory function of different inflammatory pathways.

After the successful behavioral assays, we "trained" a chemometric model to discriminate between the patterns of volatiles produced by treatment with either the 3 PAMPs (LPS, Poly(I:C), and Pam 3CSK4) and controls. Evidence in support of our hypothesis that different pathogens would promote differing and recognizable patterns of volatile metabolites would contribute an important step toward the goal of exploiting the volatile metabolome as a tool for diagnosing febrile (having symptoms of a fever) diseases. In particular, we wish to determine if it might be possible to differentiate bacterial compared to a viral infection which could be used clinically to inform proper use of antibiotic drugs in humans and other animals. 


\section{Materials and methods}

\section{Subjects}

Inbred male C57BL/6J mice were bred in our laboratory (trained biosensors) or purchased from Jackson Laboratories (urine donor subjects). The donor mice were treated as described below for urine and blood donation at 6-10 weeks old. Donors had ad libitum access to food and water before and after treatment. Biosensor mice began training at 5 weeks of age. Biosensors had ad libitum access to food but were restricted from water $23 \mathrm{~h}$ a day during behavioral experiments that employed water as a reward. Biosensors received water during and after every behavioral experiment (having $1 \mathrm{~h}$ to satiate). Because lack of adequate access to water will lead to significant loss of body condition, the body mass of biosensor mice was monitored. Animal procedures described here were approved by the Monell Internal Animal Care and Use Committee (protocols \#1174 and \#1183) and compliant with the animal care and use regulations promulgated in 9 CFR parts 1,2 , and 3 .

\section{Treatments}

To obtain urine samples for bioassay training, 20 mice were injected (0.2 mL i.p.) with $250 \mu \mathrm{g} / \mathrm{mL}$ LPS in $0.01 \mathrm{M}$ phosphate-buffered saline (PBS) solution (high dose $=2.0 \mathrm{mg} / \mathrm{kg}$ ) or PBS solution only. For critical generalization trials, 10 (each) mice were given $0.2 \mathrm{~mL}$ i.p. injections of either $6.25 \mu \mathrm{g} / \mathrm{mL}$ LPS (low dose $=0.05 \mathrm{mg} / \mathrm{kg}$ ), $250 \mu \mathrm{g} / \mathrm{mL}$ Poly(I:C) $(2 \mathrm{mg} / \mathrm{kg})$, or $250 \mu \mathrm{g} / \mathrm{mL}$ Pam3CSK4 $(2 \mathrm{mg} / \mathrm{kg}$ ) prepared in $0.01 \mathrm{M}$ PBS solution.

\section{Inflammation monitoring}

Blood was collected from a subset (15) of donor mice at $2 \mathrm{~h}$ post-treatment under $2 \%$ isoflurane anesthesia via tail vein in microcentrifuge tubes containing $3.8 \% \mathrm{w} / \mathrm{v}$ sodium citrate solution. Blood was immediately centrifuged and plasma removed. Plasma was stored at $-40{ }^{\circ} \mathrm{C}$ until use for enzyme-linked immunosorbent assays (ELISA) for TNF and IL-1 $\beta$ using Quantikine ELISA kits as directed by the manufacturer (R\&D Systems, Minneapolis, MN). Body mass data were also collected from these subjects and all data were analyzed by ANOVA to determine if parameters were impacted by treatment.

\section{Urine collection}

Urine was collected daily from mice by application of gentle abdominal pressure, as described elsewhere (Yamazaki et al. 1983; Millet et al. 2018). Once collected, urine was immediately stored at $-20^{\circ} \mathrm{C}$ pending behavioral or chemometric analysis. Urine was collected daily from days 4 to 28 days following treatment. Urine samples were not collected before day 4 so that any effects of fasting (food intake declines for about $48 \mathrm{~h}$ following treatment with LPS for example) and anesthesia (isoflurane used for blood collection) were minimized in the odor profile of the urine samples.

\section{Behavioral assay}

Odor discrimination tasks by a panel of 6 trained biosensors were conducted using a Y-maze apparatus, in which mice are presented with a choice of 2 urine odors. The odor training and generalization steps were described previously (Yamazaki et al. 2002). Briefly, the air was conducted through 2 odor chambers, containing urine $(0.5 \mathrm{~mL})$ exposed in $35 \mathrm{~mm}$ Petri dishes $(11 \mathrm{~mL})$ to the 2 arms of the maze. To attain necessary volumes for bioassay (particularly for rewarded training trials), urines collected from the same individual on multiple collection days were often combined. Samples representing different donors from specific treatments were randomly assigned to the left or right odor boxes of the Y-maze for each trial. Gates were manually raised and lowered in a timed sequence to permit the training or testing of each mouse in training sessions generally consisting of 35-50 two-choice trials. During training, biosensors were given a water reward (approx. $10 \mu \mathrm{L}$ ) for going to the arm of the Y-maze scented by urine odor from LPS $(2 \mathrm{mg} / \mathrm{kg})$-treated donors (4-28 days post injection) when the other arm was scented by urine odors of PBS-treated donors (1-28 days post injection).

Testing of novel stimuli (urine stimuli collected from mice never before encountered by the trained mice) in the Y-maze relies on the tendency of trained biosensors to seek the learned odor-associated with reward. That is, trained biosensors will choose the maze arm scented with novel stimuli that perceptually resemble the training stimuli. This is achieved by training biosensors to associate odor A with a reward when presented opposite of odor B in the Y-maze. Following training, subsequent unrewarded comparisons between a novel odor and odor B yield information regarding relationships between the novel odor and the training odor (odor A).

Mice were trained to associate a reward with a selection of urine odor from LPS-treated mice (odor A) when presented in comparison with urine odor from PBS-treated mice (odor B). Training consisted of reinforcing the selection of the arm of the maze scented by LPS odor by providing thirsty mice with a drop of water upon correct selection. When they reliably (greater than $80 \%$ of the trials) chose the arm scented by LPS odor, validation and generalization trials with novel stimuli commenced. Each session began with a series of rewarded trials using training stimuli. Generalization trials were initiated after 6 consecutive (or 8 of 9) correct rewarded trials. If the mouse did not achieve the required performance in rewarded trials, the session was terminated and re-established the next day. Trained mice were never reinforced with water in generalization trials regardless of Y-maze arm selection.

The first generalization trials, termed validation trials, were designed to determine whether the mice learned to differentiate treatment with LPS from treatment with PBS-as opposed to learning about individual identities of urine donors. This is a necessary evaluation even though the donor mice are inbred and hence assumed to be genetically identical. Upon correct selection of odors of novel LPS-treated mice, we can conclude that the mice have learned that LPS treatment produces urine odor that is different than that produced by PBS treatment. Validation trials were conducted with urines collected from novel LPS $(2 \mathrm{mg} / \mathrm{kg}$ ) and PBS-treated donors.

Following evidence from validation trials that trained biosensors were selecting the maze arm containing LPS-derived odor in favor of PBS-derived odors, generalization trials were conducted to test the hypothesis that activation of cellular immunity induces distinctive changes in mouse volatile profiles according to the TLR-initiated pathway. Just as urine odor associated with LPS treatment (odor A) was presented in the Y-maze versus urine odor associated with PBS treatment (odor B), test odors were always presented versus odor $\mathrm{B}$ in generalization trials. In this way, we tested the extent to which treatment with Poly(I:C), Pam3CSK4, or low-dose LPS produces urine odors perceived as similar to odors elicited by treatment with LPS (odor A). Owing to generalization behavior, if trained mice perceived Poly(I:C) odor to be similar to LPS odor we would expect the trained mice to select the arm of the Y-maze scented with urine from Poly(I:C)-treated mice in search of the LPS odor-associated reward. This same prediction would hold for other test odors (i.e., urine from Pam3CSK4 or low-dose LPS-treated mice). Conversely, if the test odor is not 
perceptively similar to the learned LPS odor, we would not expect the trained mice to select the Y-maze arm scented with the test odor in search of the water reward. Trials with urines collected from mice treated with Poly(I:C) or Pam3CSK4 were interspersed in the same testing sessions. These were followed by additional sessions employing trials with urines collected from mice treated with low-dose LPS.

\section{Behavioral data analysis}

For each set of generalization trials, responses coded as "correct" (selection of the PBS urine odor B was coded as "incorrect") were divided by the total (correct plus incorrect) number of trials. These data from all biosensors were combined. Each data set representing a unique generalization experiment contained $n \geq 75$ total trials. Data were then subject to 2-tailed binomial proportion hypothesis testing using the PROC FREQ function of SAS Studio. Significance was determined by the exact test of binomial proportion. An analysis of variance (ANOVA) was also conducted to determine if all biosensor mice in this study responded similarly to the treatment urines and if responses differed according to treatment using ratios as the response and trained mouse ID and treatment as fixed effects.

\section{Headspace GC/MS}

Following completion of behavioral sessions, 92 available urine samples representing 4 LPS, 7 control, 5 Poly(I:C), and 8 Pam3CSK4 donors were subjected to volatile analyses. Twenty-five $\mu \mathrm{L}$ samples of urine were placed in $20-\mathrm{mL}$ headspace vials and fortified with $10 \mu \mathrm{L}$ of an internal standard consisting of $10 \mu \mathrm{g} / \mathrm{mL} \mathrm{L}$-carvone in water (such that $100 \mathrm{ng}$ was delivered to each sample). At least 3 urine samples (collected 4-28 days post-treatment) from each subject were analyzed by headspace gas chromatography/mass spectrometry (GC/MS). Quality control samples consisting of empty vials or vials containing only $100 \mathrm{ng}$ of L-carvone were also analyzed throughout each chromatographic run (usually consisting of 24 urine samples). Quality control samples were used to monitor chromatographic system suitability and assist in the exclusion of chromatographic peaks not related to urine. Samples were analyzed using a HT3 dynamic headspace analyzer (Teledyne Tekmar) with a Supelco Trap K Vocarb 3000 thermal desorb trap (Sigma-Aldrich) attached to a Trace Ultra gas chromatograph (Thermo Scientific) equipped with a single quadrupole mass spectrometer (ISQ, Thermo Scientific). Samples were incubated at $40^{\circ} \mathrm{C}$ and swept with helium for $10 \mathrm{~min}$ at $75 \mathrm{~mL} / \mathrm{min}$ as volatile metabolites were collected on the thermal trap. After collection of volatiles, the trap was heated to $260{ }^{\circ} \mathrm{C}$ and volatiles were desorbed directly onto the gas chromatograph equipped with $30 \mathrm{~m} \times 0.25 \mu \mathrm{m}$ Stabilwax-DA (Restek) capillary column. Split injections $(5: 1)$ were made with a column flow of $2.0 \mathrm{~mL} / \mathrm{min}$ and a split vent flow of $10.0 \mathrm{~mL} / \mathrm{min}$. The $\mathrm{GC}$ oven began at $40^{\circ} \mathrm{C}(3 \mathrm{~min})$ and ramped to $260{ }^{\circ} \mathrm{C}$ at a rate of $7{ }^{\circ} \mathrm{C} / \mathrm{min}$. The mass spectrometer was operated in scan mode from 33-400 $\mathrm{m} / \mathrm{z}$. Tentative chromatographic peak identifications were based on the NIST Standard Reference Database.

\section{Chemometric analyses}

Chromatographic data were exported to MetAlign software for peak alignment and noise elimination (Lommen 2009). The resulting data were analyzed by MSClust for mass spectral extraction and assignment of a single peak response value based on the extracted selected ion monitoring (SIM) trace (Tikunov et al. 2012). Peak responses were normalized to the L-carvone response from each sample.
Data were subjected to principal components analysis (PCA) using Unscrambler (CAMO Software; Oslo, Norway) to visually identify outliers exhibiting undue influence or leverage in residual plots.

Subject means (from analysis of multiple samples from the same donor) were calculated and subjected to stepwise linear discriminant analysis (LDA) model building using PROC STEPDISC in SAS. Contingency tables for treatment classifications were constructed using PROC DISCRIM with cross-validation to determine the overall validity and error rate of the model. Mean carvonestandardized peak responses of predictors identified by the model building were calculated for each treatment for graphical presentation of the volatile patterns associated with each PAMP.

\section{Results}

\section{Treatments induced inflammation}

Mice displayed evidence of illness for 24-72 h following treatment with each PAMP. Effects included lethargy, reduced grooming, and anorexia. Mice treated with a high dose of LPS lost the most body mass in the early days following treatment (Figure 2A). The inflammatory cytokines produced in response to treatment with Poly(I:C), Pam3CSK4, or low-dose LPS were lower than counterparts receiving the $2.0 \mathrm{mg} / \mathrm{kg}$ LPS high dose (Figure 2B). Together, these data indicate that while treatment with all 3 PAMPs induced inflammation, the inflammatory response was strongest in the $2.0 \mathrm{mg} / \mathrm{kg}$ LPS-treated mice.
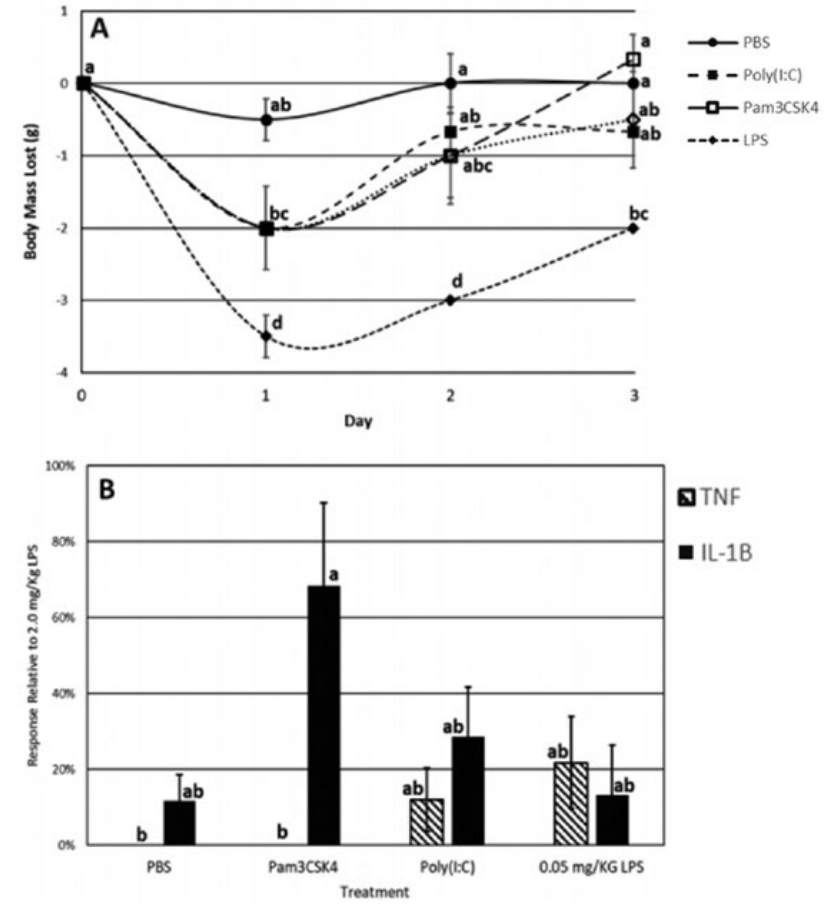

Figure 2. (A) Relative change in body mass, normalized to day 0 mass. Letters indicate differences among changes in body mass according to treatment and day. (B)TNF and IL-1B responses were found in serum $2 \mathrm{~h}$ post-treatment (as determined by ELISA) relative to responses resulting from treatment with $2.0 \mathrm{mg} / \mathrm{kg}$ LPS. Letters indicate differences among responses. All relative responses were significantly less than $100 \%(P<0.0001$ except for the value indicated with "a," $P=0.0141$ ). 


\section{Behavioral assays}

Biosensors correctly recognized the urine odors of novel mice (mice whose urine odors of LPS or PBS were never previously experienced) $73 \%$ of the time in validation trials which indicated that the training was not specific to the individual urine donors used during training (Figure 3; black bar). That is, the mice learned the urine odor differences between treatment with LPS-induced inflammation and control (PBS), not the unique individual odors of the donor mice. In contrast, mice did not generalize this learning to urine odors associated with inflammation caused by treatment with Poly(I:C) or Pam3CSK4 (Figure 3; middle bars). Biosensors generalized to Pam3CSK4-urine odor only $31 \%$ of the time, and to Poly(I:C) urine odor only $34 \%$ of the time. Both of these identification rates were significantly lower than that expected by chance $(P=0.00061$ and $P=0.0026$, respectively). This indicates that biosensors perceived the urine odor of both these treatments to be different than LPS-induced urine odor.

Generalization trials with low-dose LPS were used to test whether simple variations in the severity of inflammation might be coded differently. Mice generalized to low-dose LPS $65 \%$ of the time $(P=0.0080)$, indicating that these urines smelled very similar to the training odor (Figure 3; right bar). ANOVA results indicated that responses did not differ among the trained biosensors $(P=0.624)$ and confirmed that responses differed among treatments $(P=0.0009)$. Specifically, responses did not differ between validation and lowdose trials $(P=0.4124)$, nor did responses differ between Poly(I:C) and Pam3CSK4 $(P=0.9563)$. However, the responses to these PAMPs were lower than both validation trials with $2.0 \mathrm{mg} / \mathrm{kg}$ LPS validation trials and low-dose $(0.05 \mathrm{mg} / \mathrm{KG})$ LPS trials (Figure 3$)$.

Trained mice demonstrated that LPS urine odor is perceptively different from both Poly(I:C) and Pam3CSK4. However, these behavioral trials cannot determine whether Poly(I:C) and Pam3CSK4 are different from each other. Generalization of the learned response also shows that high- and low-dose LPS odor share odor characteristics. However, we cannot conclude that they would not be discriminated if other test procedures were employed.

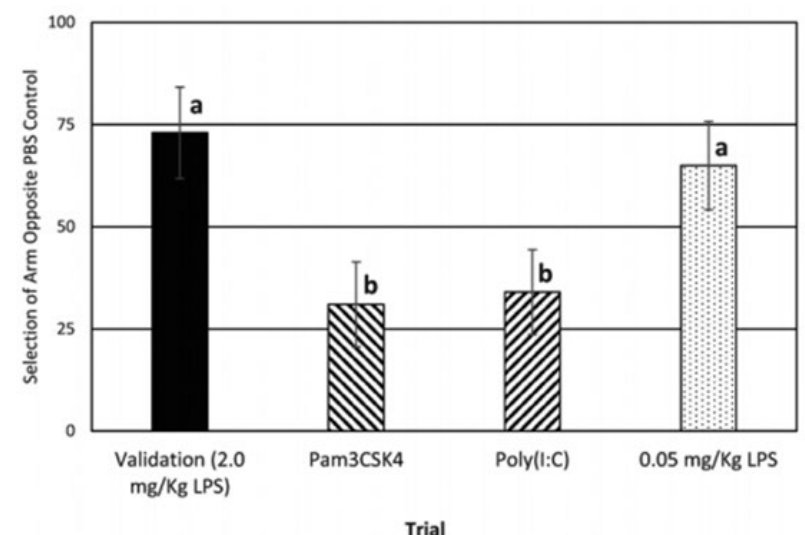

Figure 3. Mean responses of biosensors in the Y-maze apparatus in unrewarded, blind generalization trials (with 95\% confidence intervals). All biosensors were trained to select the arm of the Y-maze scented by urine odors of mice treated with high-dose $(2.0 \mathrm{mg} / \mathrm{kg})$ LPS in a 2-choice paradigm where the alternative side of the maze is scented by mice given a control PBS vehicle treatment. Responses differed among treatments $(P=0.0009)$ and responses with different letters were significantly different from each other $(\alpha=0.05)$.

\section{Chemometric model}

Peak response data from 9 (of 92) samples were determined to be outliers and one sample analysis was incomplete (no visible peaks in the chromatogram). Forty-nine peaks (not including the carvone internal standard) were determined to be of sample origin as they did not occur in the quality control samples. All tentatively identified urine volatiles were previously reported in mouse urine (Willse et al. 2005; Kwak et al. 2008). The LDA model yielded a 5-peak model capable of discriminating among LPS, Poly(I:C), Pam3CSK4, and control treatments (Table 1). The model had an average squared canonical correlation of 0.600 and a cross-validation error rate of $21.5 \%$, indicating that samples were classified to the correct treatment $78.5 \%$ in out of sample testing. Predictors were tentatively identified as o-toluidine, 5-hepten-2-one, 6-methyl-3-heptanone, 2-ethyl-1-hexanol, and dimethylsulfone (Figure 4).

\section{Discussion}

Previous studies demonstrate that various inflammatory stimuli differ in how they influence the mouse urinary volatile profile (Kimball et al. 2014; Millet et al. 2018). Toward an explanation for these observed differences, we used complementary approaches to test the hypothesis that activation of different cellular immune response pathways results in the production of distinctive urinary volatile profiles. Owing to the design of 2-choice behavioral assays and the role of generalization in learning and memory, biosensor mice trained to discriminate LPS from PBS (control) odors would be expected to generalize their positive LPS odor response to similar odors.

Behavioral assay results (Figure 3) suggest that the patterns of volatiles produced by LPS and Poly(I:C) and by LPS and Pam3CSK4 were perceptually distinct. Since Poly(I:C) and Pam3CSK4 were not tested against each other we cannot infer whether these share similar or dissimilar odor percepts. It is noteworthy that responses to these latter 2 PAMPs favored going to the arm of the maze scented by the control (PBS) odor compared to the odor of the treated mice. This may suggest that odors of Poly(I:C) and Pam3CSK4 were so different than odor induced by LPS that the trained mice chose the control odor because it was familiar (even if PBS odor had never been reinforced). Further studies on responses of untrained mice could shed light on this result. In any case, we conclude that activation of these 2 pathways produced urinary odors that were very different than those produced by LPS activation. Based on generalization results associated with the odor of the low-dose LPS, we can also conclude that differences in volatile patterns observed here (and in previous studies) from the administration of different stimuli are unlikely due solely to differences in inflammation intensity produced by the immunogen (Figure 3). However, we cannot completely rule out that the volatile metabolome may be influenced in some manner by the intensity of the inflammatory response.

Unlike discriminations made by trained animals in the Y-maze, chemometric comparisons do not share the maze's limitation of binary choice or the need to make inferences based on generalization behavior. Rather, multi-level comparisons are possible. Using the chromatographic data from treatment with LPS, Pam3CSK4, Poly(I:C), or PBS, the LDA model demonstrated that patterns of 5 key volatiles differ significantly among the treatments in a manner that could be used to predict which TLR pathway was initiated (Table 1 and Figure 4). These same volatiles have been implicated in previous studies of the volatile metabolome and inflammation. For example, 2-ethyl-1-hexanol and 6-methyl-3-heptanone were both 
Table 1. The number of urine donors assigned to each treatment by the linear discriminant analysis (LDA) model constructed from the chromatographic peak responses of 5 odorants (see Figure 4)

\begin{tabular}{lllll}
\hline \multicolumn{1}{c}{ To: } & LPS (TLR4) & Pam3CSK4 (TLR1/2) & Poly(I:C) (TLR3) & \\
\cline { 1 - 2 } From: & & & & PBS (Control) \\
\hline LPS & 4 & 0 & 0 & 0 \\
Pam3CSK4 & 0 & 7 & 4 & 1 \\
Poly(I:C) & 0 & 0 & 0 & 7 \\
PBS & 0 & 0 & 0 & 7 \\
\hline
\end{tabular}

Twenty-two of 24 urine donors were correctly classified according to treatment (TLR responsible for pathogen recognition indicated in parentheses).

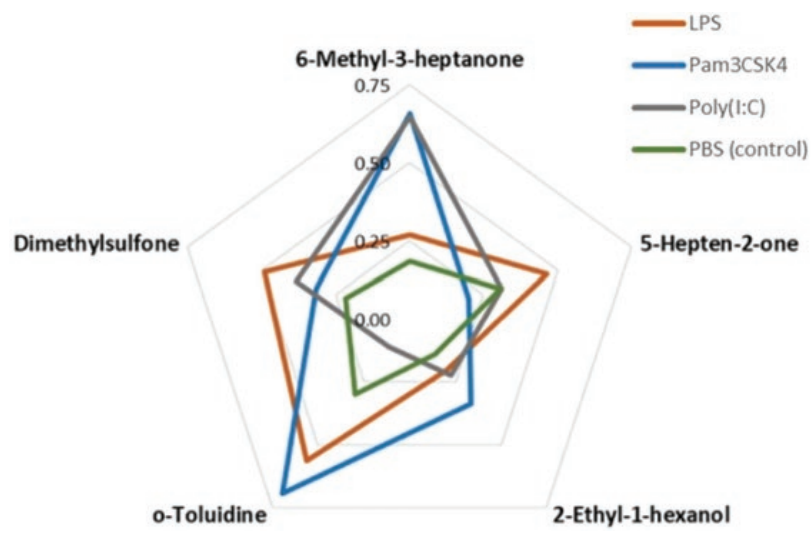

Figure 4. Radar plot of mean standardized peak responses the 5 compounds identified in the linear discriminant analysis model (see Table 1). Peak responses are standardized to the carvone internal standard. Thus, a standardized peak response of 0.5 is $50 \%$ of the response observed for carvone added to that sample. For ease of presentation, standardized peak responses were increased $5 \times$ for 6-methyl-3-heptanone and o-toluidine and $20 \times$ for dimethylsulfone.

identified in previous metabolomic studies of LPS (Gervasi et al. 2018; Millet et al. 2018). Similarly, o-toluidine and dimethylsulfone were identified in a study of murine traumatic brain injury models (Kimball et al. 2016). Importantly, we cannot conclude that mice used these same 5 odorants in the behavioral assays. More generally, the odorants mediating olfactory discrimination and that volatiles identified in the chemometric studies may not be the same. Further work is required to address this issue.

Our results suggest that pathogen recognition by specific TLRs may dictate the pattern of volatile metabolites and are consistent with the possibility that bacterial and viral infections result in diagnostically relevant alterations of the volatile metabolome. Just as TLR recognition of LPS by TLR4, Poly(I:C) by TLR3, and Pam3CSK4 by TLR1/2 results in unique alterations of the volatiles in this study, it may also be the case that TLR recognition of gram-negative bacteria by TLR4, viral RNA by TLR3, and gram-positive bacteria by TLR1/2 would do likewise. However, our results do not yield insight into how MyD88 and TRIF pathways specifically contribute to alterations of the volatile metabolome resulting from cellular immunity.

One important purpose of studying the mechanisms underlying the production of distinctive volatile profiles is the light this work may shed on differential disease diagnosis. Differential diagnoses can be challenging in certain medical conditions. For example, more rapid differential diagnosis in sepsis and systemic inflammatory response syndrome (SIRS) would be of great benefit to patients. Delaying antimicrobial treatment for septic patients by a matter of hours significantly increases the risk of mortality (Barie et al. 2005; Morrell et al. 2005; Kumar et al. 2006). As a result, standard emergency medical intervention for patients suspected of sepsis is immediate treatment with broad spectrum antimicrobials, before any microbiological testing confirming the identity or existence of the responsible pathogens (Angus and van der Poll 2013; Dellinger et al. 2013). Lack of differential diagnosis in these conditions and others can lead to unnecessary treatments with antibiotics and antimicrobials not targeted to the specific causative pathogen. This unnecessary treatment can subject patients to potentially toxic side effects, and contribute to the rise of treatment-resistant microorganisms.

The differential diagnosis of febrile diseases is specially challenging in low-resource environments (WHO 2018). In particular, it is often difficult to determine whether there is a bacterial or a nonbacterial cause for a child who presents with a fever. For example, following the exclusion of malaria as the cause of fever in areas where malaria is endemic, identifying whether or not febrile illness with fever is caused by a bacterium or virus is a key first step for guiding treatment. Routine default treatment with antibiotics, "just to be on the safe side," is particularly common in low and middleincome countries. In addition to the higher fatality rates from drugresistant infections, children with drug-resistant infections require more expensive treatments which can have more adverse effects and excess and prolonged hospitalizations.

Diagnostic tests for febrile diseases have been broadly classified into pathogen-specific and pathogen nonspecific tests (Bhaskaran et al. 2019). Pathogen-specific assays have the goal of diagnosing the specific disease that is causing the presenting fever that may be accompanied by other symptoms such as cough, diarrhea, and general malaise. In contrast, pathogen nonspecific assays are markers that only differentiate bacterial from nonbacterial causes of fever. The vast majority of biomarkers currently being evaluated to discriminate bacterial from nonbacterial causes of acute febrile illness involve hematological factors, inflammatory molecules, cytokines, cell surface and metabolic markers, and various combinations of these markers (Dittrich et al. 2016; Kapasi et al. 2016). These biomarkers are typically collected from blood and plasma. While molecular techniques for both bacteria and viruses hold great promise for specific disease diagnosis, they too often suffer from high technical barriers in terms of cost as well as complexity and need for advanced technical support and know-how.

Our results suggest that analysis of urine volatiles could potentially allow rapid differential diagnosis between pathogens, or at minimum, between certain classifications of pathogens (Figure 5). This could allow for more targeted treatments in cases where the differential diagnosis is currently difficult. Based on this present study, we can conclude there is at least more than one type of inflammatory odor profile. This suggests that many pathogens, or at least 


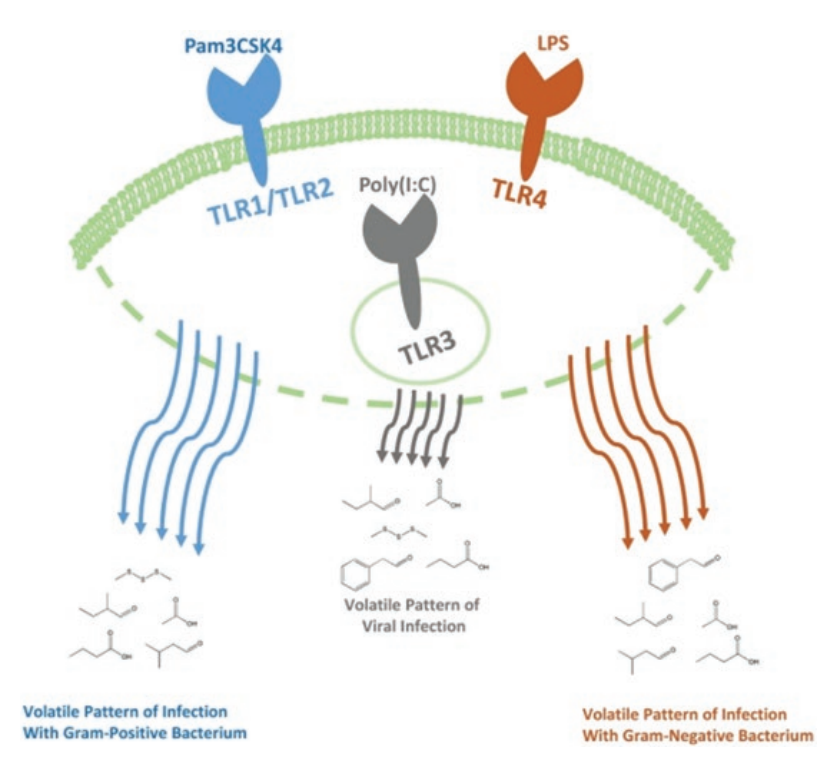

Figure 5. Pathogens are recognized by toll-like receptors to initiate a cascade of chemokines, cytokines, and other metabolites. The resulting volatile metabolites may be used to determine the source of the infection. Lipopolysaccharide (LPS), Pam3CSK4, and Poly(I:C) were used to trigger cellular immunity through recognition by TLR4, TLR1/2, and TLR 3 (respectively) to promote alterations of urinary volatiles in mice. Mouse behavioral studies indicate that mice could smell the difference between LPS-induced odors and odors induced by treatments of each of the other pathogens. The chemometric model could discriminate from among patterns of volatiles induced by treatments of all 3 of these pathogens.

classes of pathogens, will have distinct body odor volatile profiles. Our research indicates that analysis of volatile metabolites has the potential as a differential diagnostic tool. Our data suggest that alteration of body odor as a result of inflammation does not represent a generalized physiological response that occurs regardless of the initial source of the inflammation. Instead, different pathogens result in different volatile metabolite patterns. Future research is needed to further clarify how dissimilar a pathogen must be for differential diagnosis from analysis of the volatile metabolome. We believe this finding is encouraging for the future of volatile metabolomic analysis as a medical diagnostic tool.

\section{Funding}

This work was supported by the Pennsylvania Department of Health [4100077085], the National Institute on Deafness and Other Communication Disorders of the National Institutes of Health [T32DC000014], and a philanthropic gift to the Monell Center from James Albrecht (in honor of GKB). At the time the work was conducted, BK was supported by intramural funding of the United States Department of Agriculture (USDA).

\section{Acknowledgments}

The content is solely the responsibility of the authors and does not necessarily represent the official views of the National Institutes of Health. Animal work was performed at the Monell Behavioral and Physiological Phenotyping Core, which is supported, in part, by funding from the NIH-NIDCD Core Grant [1P30DC011735-01]. We acknowledge infrastructure grant [G20OD020296] "Improvements to the animal facility HVAC system at the Monell Chemical Senses Center" for its support of the Monell vivarium, where animals for this manuscript were housed.

\section{References}

Alexopoulou L, Holt AC, Medzhitov R, Flavell RA. 2001. Recognition of double-stranded RNA and activation of NF-kappaB by Toll-like receptor 3. Nature. 413(6857):732-738.

Aliprantis AO, Yang RB, Mark MR, Suggett S, Devaux B, Radolf JD, Klimpel GR, Godowski P, Zychlinsky A. 1999. Cell activation and apoptosis by bacterial lipoproteins through Toll-like receptor-2. Science. 285(5428):736-739.

Amann A, Costello Bde L, Miekisch W, Schubert J, Buszewski B, Pleil J, Ratcliffe N, Risby T. 2014. The human volatilome: volatile organic compounds (VOCs) in exhaled breath, skin emanations, urine, feces and saliva. J Breath Res. 8(3):034001.

Angus DC, van der Poll T. 2013. Severe sepsis and septic shock. N Engl J Med. 369(9):840-851.

Arakawa H, Arakawa K, Blandino P Jr, Deak T. 2011a. The role of neuroinflammation in the release of aversive odor cues from footshockstressed rats: Implications for the neural mechanism of alarm pheromone. Psychoneuroendocrinology. 36(4):557-568.

Arakawa H, Arakawa K, Deak T. 2009a. Acute illness induces the release of aversive odor cues from adult, but not prepubertal, male rats and suppresses social investigation by conspecifics. Behav Neurosci. 123: 964-978.

Arakawa H, Arakawa K, Deak T. 2010. Sickness-related odor communication signals as determinants of social behavior in rat: a role for inflammatory processes. Horm Behav. 57(3):330-341.

Arakawa H, Blandino P Jr, Deak T. 2009b. Central infusion of interleukin-1 receptor antagonist blocks the reduction in social behavior produced by prior stressor exposure. Physiol Behav. 98(1-2):139-146.

Arakawa H, Cruz S, Deak T. 2011b. From models to mechanisms: odorant communication as a key determinant of social behavior in rodents during illness-associated states. Neurosci Biobehav Rev. 35(9):1916-1928.

Bajtarevic A, Ager C, Pienz M, Klieber M, Schwarz K, Ligor M, Ligor T, Filipiak W, Denz H, Fiegl M, et al. 2009. Noninvasive detection of lung cancer by analysis of exhaled breath. BMC Cancer. 9:348.

Baldwin AS Jr. 1996. The NF-kappa B and I kappa B proteins: new discoveries and insights. Annu Rev Immunol. 14:649-683.

Barie PS, Hydo LJ, Shou J, Larone DH, Eachempati SR. 2005. Influence of antibiotic therapy on mortality of critical surgical illness caused or complicated by infection. Surg Infect (Larchmt). 6(1):41-54.

Beeson PB; Technical Assistance of Elizabeth Roberts. 1947. Tolerance to bacterial pyrogens: I. Factors influencing its development. J Exp Med. 86(1):29-38.

Bernabei M, Pennazza G, Santortico M, Corsi C, Roscioni C, Paolesse R, Di Natale C, D’Amico A. 2008. A preliminary study on the possibility to diagnose urinary tract cancers by an electronic nose. Sensors Actuators $B$ Chem. 131:1-4.

Bhaskaran D, Chadha SS, Sarin S, Sen R, Arafah S, Dittrich S. 2019. Diagnostic tools used in the evaluation of acute febrile illness in South India: a scoping review. BMC Infect Dis. 19(1):970.

Bijland LR, Bomers MK, Smulders YM. 2013. Smelling the diagnosis: a review on the use of scent in diagnosing disease. Neth J Med. 71(6):300-307.

Brennan PA, Kendrick KM. 2006. Mammalian social odours: attraction and individual recognition. Philos Trans $R$ Soc Lond B Biol Sci. 361(1476):2061-2078.

Brightbill HD, Libraty DH, Krutzik SR, Yang RB, Belisle JT, Bleharski JR, Maitland M, Norgard MV, Plevy SE, Smale ST, et al. 1999. Host defense mechanisms triggered by microbial lipoproteins through toll-like receptors. Science. 285(5428):732-736.

Burdette SD, Bernstein JM. 2007. Does the nose know? The odiferous diagnosis of Clostridium difficile-associated diarrhea. Clin Infect Dis. 44(8):1142.

Choi HJ, Kim MK, Ko JH, Lee HJ, Jeong HJ, Wee WR, Seong SY, Akira S. 2011. Effect of Toll-like receptor 2 and 4 of corneal fibroblasts on cytokine expression with co-cultured antigen presenting cells. Cytokine. 56(2):265-271.

Dellinger RP, Levy MM, Rhodes A, Annane D, Gerlach H, Opal SM, Sevransky JE, Sprung CL, Douglas IS, Jaeschke R, et al.; Surviving Sepsis Campaign Guidelines Committee including the Pediatric Subgroup. 2013. 
Surviving sepsis campaign: international guidelines for management of severe sepsis and septic shock: 2012. Crit Care Med. 41(2):580-637.

Dittrich S, Tadesse BT, Moussy F, Chua A, Zorzet A, Tängdén T, Dolinger DL, Page AL, Crump JA, D'Acremont V, et al. 2016. Target product profile for a diagnostic assay to differentiate between bacterial and non-bacterial infections and reduce antimicrobial overuse in resource-limited settings: An expert consensus. PLoS One. 11(8):e0161721.

Geppert TD, Whitehurst CE, Thompson P, Beutler B. 1994. Lipopolysaccharide signals activation of tumor-necrosis-factor biosynthesis through the RAS/ RAF-1/MEK/MAPK Pathway. Mol Med. 1:93-103.

Gervasi SS, Opiekun M, Martin T, Beauchamp GK, Kimball BA. 2018. Sharing an environment with sick conspecifics alters odors of healthy animals. Sci Rep. 8(1):14255.

Greiter MB, Keck L, Siegmund T, Hoeschen C, Oeh U, Paretzke HG. 2010. Differences in exhaled gas profiles between patients with type 2 diabetes and healthy controls. Diabetes Technol Ther. 12(6):455-463.

Häcker H, Redecke V, Blagoev B, Kratchmarova I, Hsu LC, Wang GG, Kamps MP, Raz E, Wagner H, Häcker G, et al. 2006. Specificity in Tolllike receptor signalling through distinct effector functions of TRAF3 and TRAF6. Nature. 439(7073):204-207.

Jezierski T, Walczak M, Ligor T, Rudnicka J, Buszewski B. 2015. Study of the art: canine olfaction used for cancer detection on the basis of breath odour. Perspectives and limitations. J Breath Res. 9(2):027001.

Johnston RE. 2003. Chemical communication in rodents: From pheromones to individual recognition. J Mammal. 84:1141-1162.

Kapasi AJ, Dittrich S, González IJ, Rodwell TC. 2016. Host biomarkers for distinguishing bacterial from non-bacterial causes of acute febrile illness: a comprehensive review. PLoS One. 11(8):e0160278.

Kavaliers M, Choleris E, Pfaff DW. 2005. Recognition and avoidance of the odors of parasitized conspecifics and predators: differential genomic correlates. Neurosci Biobehav Rev. 29(8):1347-1359.

Kelliher KR. 2007. The combined role of the main olfactory and vomeronasal systems in social communication in mammals. Horm Behav. 52(5):561-570.

Kimball BA. 2016. Volatile metabolome: problems and prospects. Bioanalysis. 8(19):1987-1991.

Kimball BA, Cohen AS, Gordon AR, Opiekun M, Martin T, Elkind J, Lundström JN, Beauchamp GK. 2016. Brain injury alters volatile metabolome. Chem Senses. 41(5):407-414.

Kimball BA, Opiekun M, Yamazaki K, Beauchamp GK. 2014. Immunization alters body odor. Physiol Behav. 128:80-85.

Kumar A, Roberts D, Wood KE, Light B, Parrillo JE, Sharma S, Suppes R, Feinstein D, Zanotti S, Taiberg L, et al. 2006. Duration of hypotension before initiation of effective antimicrobial therapy is the critical determinant of survival in human septic shock. Crit Care Med. 34(6):1589-1596.

Kwak J, Willse A, Matsumura K, Curran Opiekun M, Yi W, Preti G, Yamazaki K, Beauchamp GK. 2008. Genetically-based olfactory signatures persist despite dietary variation. PLoS One. 3(10):e3591.

Lommen A. 2009. MetAlign: interface-driven, versatile metabolomics tool for hyphenated full-scan mass spectrometry data preprocessing. Anal Chem. 81(8):3079-3086.
Lu YC, Yeh WC, Ohashi PS. 2008. LPS/TLR4 signal transduction pathway. Cytokine. 42(2):145-151.

Mahoney A, Weetjens BJ, Cox C, Jubitana M, Kazwala R, Mfinanga GS, Durgin A, Poling A. 2013. Giant African pouched rats as detectors of tuberculosis in human sputum: comparison of two techniques for sputum presentation. Psycholog Record. 63:21-26.

Mgode GF, Weetjens BJ, Nawrath T, Lazar D, Cox C, Jubitana M, Mahoney A, Kuipers D, Machang'u RS, Weiner J, et al. 2012. Mycobacterium tuberculosis volatiles for diagnosis of tuberculosis by Cricetomys rats. Tuberculosis (Edinb). 92(6):535-542.

Millet P, Opiekun M, Martin T, Beauchamp GK, Kimball BA. 2018. Cytokine contributions to alterations of the volatile metabolome induced by inflammation. Brain Behav Immun. 69:312-320.

Morrell M, Fraser VJ, Kollef MH. 2005. Delaying the empiric treatment of candida bloodstream infection until positive blood culture results are obtained: a potential risk factor for hospital mortality. Antimicrob Agents Chemother. 49(9):3640-3645.

Phillips M, Basa-Dalay V, Blais J, Bothamley G, Chaturvedi A, Modi KD, Pandya M, Natividad MP, Patel U, Ramraje NN, et al. 2012. Point-of-care breath test for biomarkers of active pulmonary tuberculosis. Tuberculosis (Edinb). 92(4):314-320.

Raetz CR, Whitfield C. 2002. Lipopolysaccharide endotoxins. Annu Rev Biochem. 71:635-700.

Schaefer ML, Young DA, Restrepo D. 2001. Olfactory fingerprints for major histocompatibility complex-determined body odors. J Neurosci. 21(7):2481-2487.

Takaoka A, Yanai H, Kondo S, Duncan G, Negishi H, Mizutani T, Kano S, Honda K, Ohba Y, Mak TW, et al. 2005. Integral role of IRF-5 in the gene induction programme activated by Toll-like receptors. Nature. 434(7030):243-249.

Takeda K, Akira S. 2004. TLR signaling pathways. Semin Immunol. 16(1):3-9. Tikunov YM, Laptenok S, Hall RD, Bovy A, de Vos RC. 2012. MSClust: a tool for unsupervised mass spectra extraction of chromatography-mass spectrometry ion-wise aligned data. Metabolomics. 8(4):714-718.

van Oort PM, Povoa P, Schnabel R, Dark P, Artigas A, Bergmans DCJJ, Felton T, Coelho L, Schultz MJ, Fowler SJ, et al. 2018. The potential role of exhaled breath analysis in the diagnostic process of pneumonia-a systematic review. J Breath Res. 12(2):024001.

WHO. 2018. Technology landscape report. Geneva (Switzerland): World Heath Organization. http://unitaid.org/assets/Fever_diagnostic_technology_and_ market_landscape.pdf.

Willse A, Belcher AM, Preti G, Wahl JH, Thresher M, Yang P, Yamazaki K, Beauchamp GK. 2005. Identification of major histocompatibility complex-regulated body odorants by statistical analysis of a comparative gas chromatography/mass spectrometry experiment. Anal Chem. 77(8):2348-2361.

Yamazaki K, Beauchamp GK, Egorov IK, Bard J, Thomas L, Boyse EA. 1983. Sensory distinction between $\mathrm{H}-2 \mathrm{~b}$ and $\mathrm{H}-2 \mathrm{bm} 1$ mutant mice. Proc Natl Acad Sci USA. 80(18):5685-5688.

Yamazaki K, Boyse EA, Bard J, Curran M, Kim D, Ross SR, Beauchamp GK. 2002. Presence of mouse mammary tumor virus alters the body odor of mice. Proc Natl Acad Sci USA. 99:5612-5615. 